\title{
Calf Response to Caustic Paste and Hot-Iron Dehorning Using Sedation With and Without Local Anesthetic
}

\author{
K. J. Vickers, L. Niel, L. M. Kiehlbauch, and D. M. Weary \\ Animal Welfare Program, Faculty of Agricultural Sciences, \\ The University of British Columbia, Vancouver V6T 1Z4, Canada
}

\begin{abstract}
Dairy producers require effective methods of reducing the pain associated with dehorning. Previous work has shown that analgesics can reduce pain associated with hot-iron dehorning, but these interventions may not be practical for some producers. Some producers favor the use of caustic paste (to cause a chemical burn as opposed to thermal burn), but little is known about how to treat pain caused by caustic burns. In 2 experiments, head shaking and head rubbing behaviors were used to evaluate pain following dehorning using caustic paste. In experiment 1 , sedated calves were dehorned using a caustic paste, with or without a lidocaine local block. Calves treated with lidocaine showed no evidence of reduced pain response in the hours after the caustic paste was applied. In experiment 2 , response to caustic paste dehorning with a sedative only was compared with hot-iron dehorning using a sedative and local anesthetic. In the first $4 \mathrm{~h}$ after dehorning, calves dehorned with a hot iron showed more head shaking than calves dehorned with caustic paste. These results indicate that dehorning with caustic paste combined with a sedative results in less pain to calves than dehorning with a hot iron combined with a sedative and a local anesthetic. (Key words: calves, dehorning, pain, behavior)
\end{abstract}

\section{INTRODUCTION}

Dairy cattle are typically dehorned to reduce the risk of injuries to humans and other animals. To prevent horn growth, the corium and surrounding tissue are destroyed using a variety of methods including heat cauterization, chemical cauterization, and scooping. Choice of method depends largely upon the producer's experience and preference, but heat and chemical cauterization are often used for calves dehorned within the first 8 wk of life.

Received September 1, 2004.

Accepted January 1, 2005.

Corresponding author: Daniel M. Weary; e-mail: danweary@ interchange.ubc.ca.
Behavioral and physiological responses by calves to hot-iron dehorning show evidence of handling distress associated with the physical restraint necessary to perform the procedure, pain during the dehorning, and postoperative pain during the hours that follow (e.g., Graf and Senn, 1999; Grøndahl-Nielsen et al., 1999; Faulkner and Weary, 2000). These and other studies have demonstrated that administering a combination of sedative, nerve block, and anti-inflammatory drug can reduce the pain and distress associated with this procedure.

Much less is known about the pain due to caustic paste dehorning and how this might be reduced. With caustic burns, tissue damage continues to increase as long as the active chemical is in contact with the tissue (Yano et al., 1993). In contrast, physiological and behavioral evidence from human thermal burns (Davies, 1982 ) and thermal nociception studies in cattle (Veissier et al., 2000) suggest that tissue damage is restricted to the duration and location of administration of the hot iron. Therefore, it cannot be assumed that time course, behavioral responses, and treatments for pain would be the same for both methods of dehorning.

Only one published study has examined pain due to caustic paste dehorning for calves (Morisse et al., 1995). The calves in that study showed the characteristic pain response to dehorning, including increased frequency of head shaking and scratching, but the time course of the response was not well described. Those authors compared animals dehorned by caustic paste vs. hot iron, but treatments were confounded with calf age making the results difficult to interpret.

The aims of the current study were 1) to document the time course of the postoperative pain response to caustic paste dehorning, 2) to determine the effect of a local anesthetic nerve block on this response, and, having established the more suitable method of using the paste, 3 ) to compare responses to caustic paste and hotiron dehorning.

\section{MATERIALS AND METHODS}

\section{Calf Housing and Feeding Conditions}

Thirty-six Holstein heifer calves from The University of British Columbia's Dairy Education and Research 
Center (10 to $35 \mathrm{~d}$ old) were used in this experiment. All heifers born on this farm are dehorned as part of the farm's standard practice.

Calves were housed in individual pens $(1.7 \times 1.2 \mathrm{~m})$ bedded with sawdust until they were 7 to $14 \mathrm{~d}$, at which time they were moved to group pens $(1.7 \times 4.8 \mathrm{~m})$ with 4 to 7 calves per pen. Calves in individual pens were fed milk at 5\% of BW morning and evening and had free access to hay, calf starter, and water. Calves in group pens had free access to hay, calf starter, and water, and milk was available ad libitum via a nipple system (Jasper and Weary, 2002).

At approximately $0900 \mathrm{~h}$ on the morning of the procedure, calves were weighed and moved to an individual sawdust-bedded pen $(1.7 \times 1.2 \mathrm{~m})$ in an isolated room where they had free access to water, hay, and grain. Procedures (dehorning and sham dehorning) were performed between 1000 and $1300 \mathrm{~h}$. Milk (5\% of BW) was fed by bucket in the evening and early the next morning before calves were returned to their home pens.

\section{Experimental Design}

This study consisted of 2 experiments using similar methodologies. Experiment 1 investigated the effects of using a caustic paste and sedative with or without a local anesthetic, and experiment 2 investigated the effects of hot iron dehorning with a sedative and local anesthetic vs. caustic paste dehorning with a sedative only.

Experiment 1. Calves were alternately assigned to xylazine only $(\mathrm{n}=10)$ or xylazine plus lidocaine $(\mathrm{n}=$ 10) before being dehorned with a caustic paste (Dr. Naylor's Dehorning Paste; H. W. Naylor Company, Inc., Morris, NY). To determine the effects of caustic paste dehorning as well as that of drug administration, all calves acted as their own control during sham dehorning 4 to $7 \mathrm{~d}$ before actual dehorning. During the sham procedure, calves received the sedative and the same treatment (i.e., lidocaine or no lidocaine) with identical timing, but paste was not applied to the horn bud. Instead, a thin film of petroleum jelly was rubbed into the scalp on the horn bud to simulate the paste, and a petroleum jelly ring was applied around the horn bud. Dehorning and sham dehorning were performed by the same trained individual and only one calf underwent the procedure on any one day.

For both procedures, calves were moved to an isolated pen, and they were administered the sedative xylazine (Rompun 2\%, Bayer Inc., Sarnia, Ontario, Canada) intramuscularly at $0.2 \mathrm{mg} / \mathrm{kg} 20 \mathrm{~min}$ before the procedure. Once the sedation took effect and the animal was lying sternally, the hair surrounding each horn bud was trimmed with clippers. Ten minutes before the paste was applied, calves in the lidocaine treatment group were given $9 \mathrm{~mL}$ of local anesthetic (lidocaine $\mathrm{HCl}$; Ayerst Veterinary Laboratories, Guelph, Ontario, Canada); $1.5 \mathrm{~mL}$ of lidocaine was injected subcutaneously along each occipital groove (to block the cornual nerves), and $3 \mathrm{~mL}$ was injected subcutaneously as a ring block around each horn bud. After $10 \mathrm{~min}$, a thin film of caustic paste (or petroleum jelly if sham dehorning), approximately $2 \mathrm{~cm}$ in diameter, was rubbed into the scalp until the horn bud was evenly coated. A ring of petroleum jelly was applied around the paste to prevent spread. Calves were positioned sternally and left to recover.

Experiment 2. Calves were alternately assigned to caustic paste $(n=8)$ or hot-iron dehorning $(n=8)$. Xylazine, lidocaine, and caustic paste were administered as described in experiment 1. Calves dehorned with the caustic paste received only the sedative xylazine (as in the control group in experiment 1). Calves in the hot-iron dehorning group were given both xylazine and lidocaine. A preheated hot-iron dehorner at approximately $600^{\circ} \mathrm{C}$ (Rhinehart X30, Rhinehart Development Corp., Spencerville, IN) was held on each horn bud for approximately $15 \mathrm{~s}$. For each day of the trial, 2 calves were dehorned within minutes of each other, one with a hot iron and the other with caustic paste. Each calf was dehorned in a separate but identical pen. Calves in this experiment were not sham dehorned.

\section{Video Analysis}

Calf behavior was monitored in the hours following sham and actual dehorning using a Panasonic WVBP330 camera and Panasonic AG-6540 time-lapse video recorder. Recording started 15 min after completion of the procedure and continued for $12 \mathrm{~h}$. This period was deemed long enough to encompass a full response based on preliminary studies that monitored the pain response for $24 \mathrm{~h}$ post-dehorning. During video analysis, the observer was blind to treatment, and the same trained observer made all observations for both experiments. In experiment 1 , petroleum jelly was dyed orange with food coloring so that sham-dehorned calves could not be distinguished from caustic paste-dehorned calves in videotapes. A malfunctioning of the video equipment in experiment 1 resulted in loss of data for 3 calves in the xylazine-only group and one calf in the xylazine plus lidocaine group. In experiment 2 , video problems resulted in the loss of data from one calf.

Behavior was scored continuously from video, except during the hour around evening feeding (15 min before until 45 min after the milk bucket was placed in front of the calf). As the feeding hour often overlapped 2 observational hours, the fraction of each hour that fell 

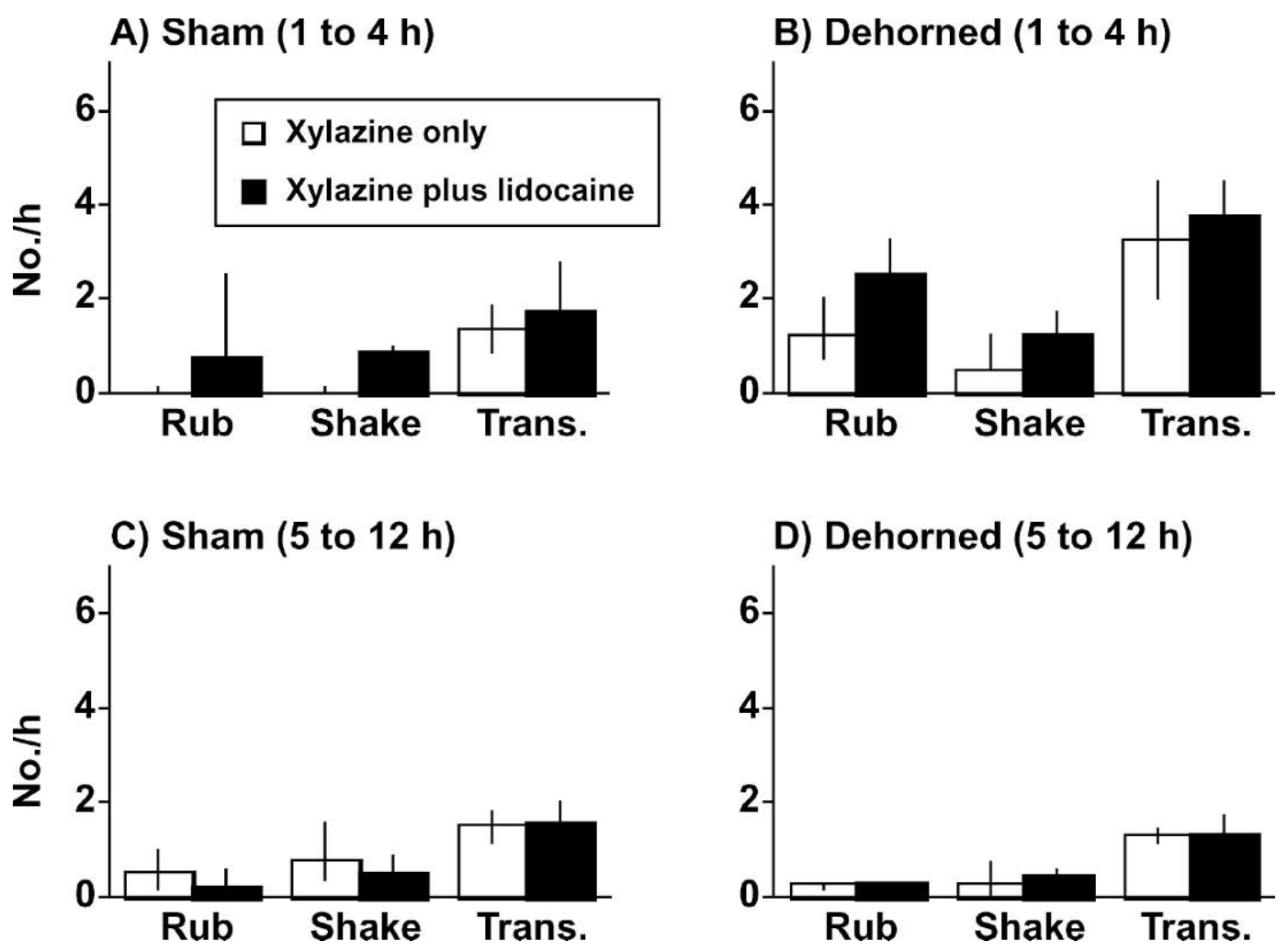

Figure 1. Experiment 1. Median and interquartile ranges for the number of head rubs (rub), head shakes (shake), and transitions (Trans.) between lying and standing (trans) for calves sham dehorned (panels A and C) and dehorned with caustic paste (parts B and D) using xylazine $(\mathrm{n}=7)$ or xylazine plus lidocaine $(\mathrm{n}=9$ ). Results are shown separately for $\mathrm{h} 1$ to 4 (panels A and B) and h 5 to 12 (panels $\mathrm{C}$ and D) after the procedure.

outside the feeding hour was combined into one "composite" hour, and this was recorded for the hour that was most heavily weighted. Feeding generally occurred 6 or $7 \mathrm{~h}$ after dehorning.

Behaviors recorded during this experiment follow those used in previous research (see Faulkner and Weary, 2000) and are typical for calves in pain following dehorning. The frequencies of 3 behaviors were monitored: head shaking, head rubbing (with the hind leg or against the sides of the pen), and transitions (standing up from lying position or lying down from standing position counted as one transition).

\section{Statistical Analyses}

Behavioral responses peaked within the first $4 \mathrm{~h}$, so data were analyzed separately for h 1 to 4 and h 5 to 12 after the procedure. Distributions of these variables tended to be non-normal, so nonparametric analyses were used. Preliminary analysis showed no effect of calf age on response to treatment so this parameter was not investigated further. The Wilcoxon signed-ranks test was used for comparisons within calf (e.g., sham vs. dehorning in experiment 1), and the Mann-Whitney
$U$-test was used for treatments tested between subjects (e.g., lidocaine vs. no lidocaine in experiment 1). All results are presented as medians with 25 th and 75 th percentiles.

\section{RESULTS}

\section{Experiment 1}

Sham-dehorned calves treated only with xylazine showed almost no head rubbing or shaking during the first $4 \mathrm{~h}$ after the procedure (Figure 1a), but calves treated with xylazine plus lidocaine showed more of these behaviors. This difference was statistically significant for the number of head rubs $\left(\mathrm{U}=11, \mathrm{~N}_{1}=7\right.$, $\left.\mathrm{N}_{2}=9, P<0.05\right)$ and head shakes $\left(\mathrm{U}=10, \mathrm{~N}_{1}=7\right.$, $\left.\mathrm{N}_{2}=9, P<0.02\right)$. There was no effect of the lidocaine treatment on the number of transitions between lying and standing for this comparison or any of the other 3 panels shown in Figure 1. During the first $4 \mathrm{~h}$ following dehorning, calves showed numerically more head rubs and shakes when treated with lidocaine, but these differences were not significant.

Given that lidocaine was found to have no positive effect, the response to sham vs. actual dehorning was 
compared using only those calves not treated with lidocaine. In terms of all response measures, these animals showed stronger responses following dehorning than following sham dehorning ( $\mathrm{T}=0, \mathrm{n}=6, P<0.05, \mathrm{~T}=$ 1.5, $\mathrm{n}=7, P<0.05$, and $\mathrm{T}=0, \mathrm{n}=7, P<0.02$ for head rubs, head shakes, and transitions, respectively).

All behavioral responses were less frequent for the period from 5 to $12 \mathrm{~h}$ after the procedure, for sham and dehorned procedures (Figure 1c and 1d). For both procedures, there was no effect of the lidocaine treatment on any of the 3 response measures, and there was no difference in response to sham and actual dehorning during this period.

\section{Experiment 2}

As in the first experiment, responses varied with time after the procedure; head shakes, head rubs, and transitions were most frequent from 1 to $4 \mathrm{~h}$ after dehorning (Figure 2). During the first $4 \mathrm{~h}$, calves dehorned with the hot iron shook their heads at more than 9 times the rate of those dehorned with the caustic paste ( $\mathrm{U}=$ $7.5, \mathrm{~N}_{1}=7, \mathrm{~N}_{2}=8, P<0.05$; Table 1). Calves in the hot-iron group performed more head rubs and had more transitions between lying and standing, but these differences were not significant.

During the period from 5 to $12 \mathrm{~h}$ after dehorning, there was no effect of the dehorning method on head rubs or shakes. However, calves dehorned using the hot iron showed over 50\% more transitions between standing and lying during this 8-h period.

\section{DISCUSSION}

Pain-related behaviors increased in 1) calves that were dehorned with caustic paste compared with calves that were sham dehorned, and 2) calves that were dehorned with a hot iron compared with those dehorned with caustic paste. These results indicate that dehorning with caustic paste causes pain, but that the pain is less than that caused by the hot iron, even when using lidocaine.

The results also indicate that head shaking, head rubbing, and transitions from standing or lying can be useful indicators of postoperative pain for both methods of dehorning. Other studies have used the frequencies of head shaking and rubbing after dehorning as indicators of pain (Graf and Senn, 1999; Grøndahl-Nielsen et al., 1999; Faulkner and Weary, 2000). Morisse et al. (1995) also monitored transitions as an indicator of pain after dehorning.

Very few studies have examined the effects of administering a sedative and a local anesthetic together to reduce pain and distress, and none to our knowledge
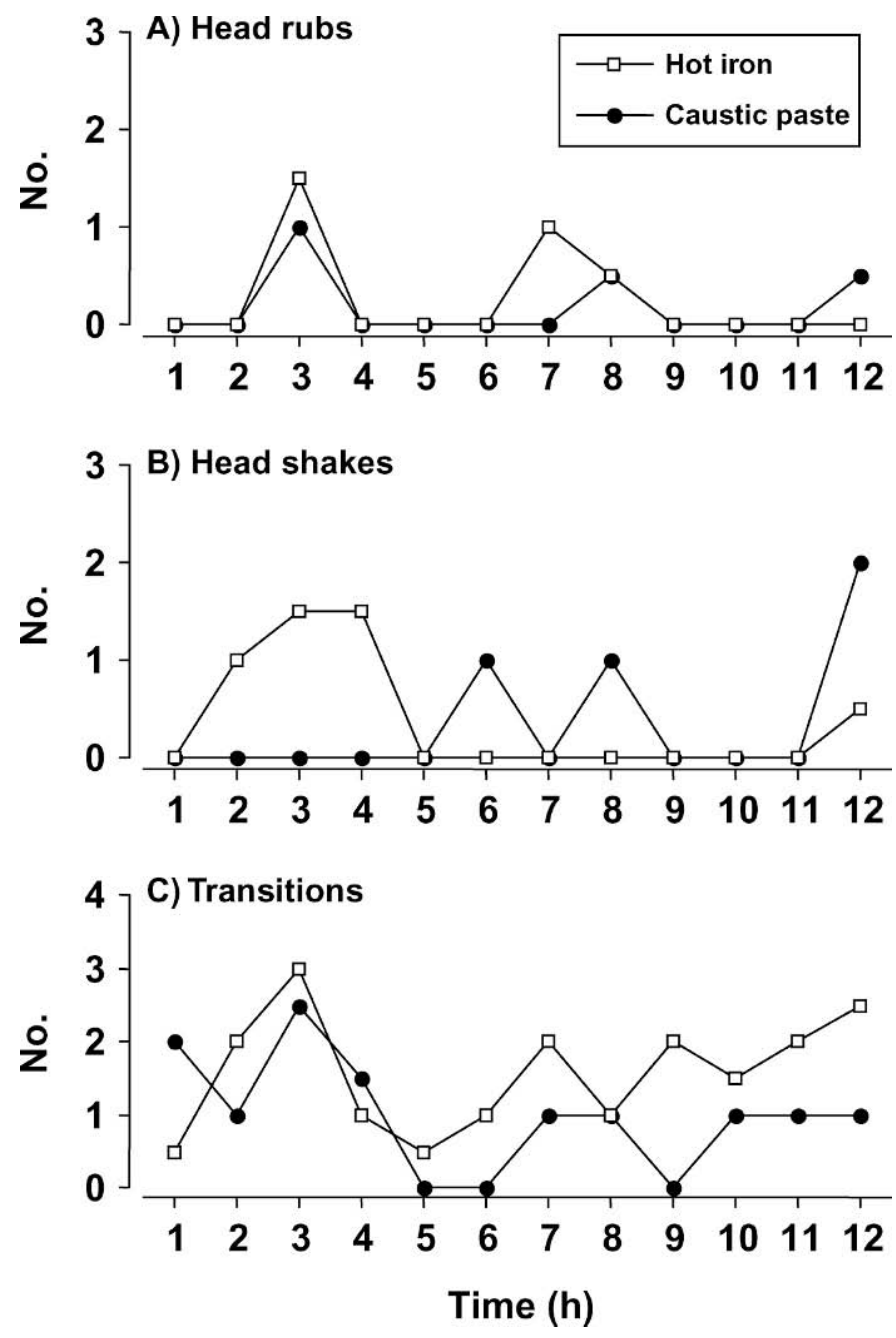

Figure 2. Experiment 2. Median numbers of head rubs, head shakes, and transitions between lying and standing for calves dehorned with hot iron (open squares; $\mathrm{n}=7$ ) or caustic paste (solid circles; $n=8$ ). Responses are shown separately for each hour of observation after dehorning.

have done so using the caustic paste method of dehorning. Grøndahl-Nielsen et al. (1999) compared calves that received either a sedative or a local anesthetic, or both, or neither, before being dehorned with a hot iron. Results showed that calves that received anesthetic showed fewer pain-related behaviors than those that did not. However, comparisons between the anestheticonly group and the group receiving a sedative and local anesthetic were not made because calves receiving the sedative remained sedated for much of the 4-h observation period that followed dehorning. In the current study, despite using the same dosage of sedative reported by Grøndahl-Nielsen et al. (1999), it was not unusual for calves to show pain-related behaviors as soon as $1 \mathrm{~h}$ after dehorning. 
Table 1. Median, 25th, and 75th percentiles for each of the 3 behavioral responses by calves dehorned with hot iron $(n=7)$ or caustic paste $(n=8)$ in experiment 2 . Responses are shown separately for $\mathrm{h} 1$ to 4 and h 5 to 12 after the procedure.

\begin{tabular}{|c|c|c|c|c|c|c|c|c|}
\hline \multirow[b]{2}{*}{ Behavior (no./h) } & \multicolumn{3}{|c|}{ Hot iron } & \multicolumn{3}{|c|}{ Caustic paste } & \multirow[b]{2}{*}{$\mathrm{U}$} & \multirow[b]{2}{*}{$P$} \\
\hline & 25 th & Med & 75th & 25 th & Med & 75th & & \\
\hline \multicolumn{9}{|l|}{ Hours 1 to 4} \\
\hline Rubs & 0.25 & 1.00 & 1.88 & 0.25 & 0.50 & 1.25 & 19.5 & $\mathrm{NS}^{1}$ \\
\hline Shakes & 0.38 & 1.25 & 2.25 & 0.00 & 0.13 & 0.88 & 7.5 & $<0.05$ \\
\hline Transitions & 1.25 & 1.88 & 2.50 & 1.00 & 1.75 & 2.75 & 26.5 & NS \\
\hline \multicolumn{9}{|l|}{ Hours 5 to 12} \\
\hline Rubs & 0.00 & 0.50 & 1.29 & 0.07 & 0.31 & 0.86 & 24 & NS \\
\hline Shakes & 0.07 & 0.43 & 0.64 & 0.29 & 0.64 & 1.00 & 21 & NS \\
\hline Transitions & 1.14 & 1.50 & 2.36 & 0.64 & 0.93 & 1.29 & 8.5 & $<0.05$ \\
\hline
\end{tabular}

${ }^{1} \mathrm{NS}=P>0.05$.

Probably, the main value of the sedative is that it eliminates the need for physical restraint during the procedure and thus eliminates distress caused by such a restraint. However, xylazine is known to have some analgesic effects (Ley et al., 1990). Although these are too weak to provide satisfactory analgesia during hotiron dehorning, they may help reduce the pain following administration of caustic paste.

It is well documented that administration of a local anesthetic greatly reduces the immediate pain response to hot iron or scoop dehorning (McMeekan et al., 1998; Sylvester et al., 1998; Stafford et al., 2003). Surprisingly, lidocaine did not reduce the painful effects of caustic paste dehorning in our study. Indeed, the elevated frequency of head rubs and shakes in sham-dehorned calves treated with lidocaine suggests that administration of the drug may cause some discomfort. From the current study, it is not clear whether the injection itself was causing discomfort, or whether the response was specific to the lidocaine.

Why lidocaine had no positive effect on reducing the pain due to the caustic paste might be explained by its mode of action. All local anesthetics are weak bases that combine with strong acids to form a salt that is stable and soluble (de Jong, 1977). To cross the hydrophobic lipid cell membrane, the salt must dissociate, but the anesthetic must reassociate once inside the nerve cell to form the cation that blocks the influx of sodium ions and prevents nerve conduction. The active ingredients in caustic paste are sodium hydroxide and calcium hydroxide, both very strong bases. As these bases destroy the tissue, the rise in $\mathrm{pH}$ may affect the equilibrium of the anesthetic solution, resulting in fewer cations available to block sodium receptors and thus, disrupting the function of the anesthetic.

The lack of benefit from the lidocaine in experiment 1 , combined with the low behavioral response to caustic paste dehorning with a sedative alone, led us to consider how this method of dehorning compares with alterna- tive methods. Hot-iron dehorning is one of the most widely used methods, and the method for which most is known regarding pain control. Pain associated with this procedure can be controlled using a local anesthetic for a cornual nerve block and a ring block around the horn bud. Longer postoperative pain relief for hot-iron dehorning can be provided by longer-acting local blocks (e.g., bupivicaine) or by providing nonsteroidal antiinflammatories (such as ketoprofen; e.g., Milligan et al., 2004).

Given that responses in experiment 1 peaked during the first $4 \mathrm{~h}$ after the procedure, responses in experiment 2 were considered separately for this period, and for the subsequent $8 \mathrm{~h}$. Results from experiment 2 indicated that the simpler and less invasive method of caustic paste dehorning resulted in a lower pain response than using a hot iron with sedative and local anesthetic. It is likely that the response to the hot-iron method would be further reduced if nonsteroidal anti-inflammatories drugs were provided, especially in $\mathrm{h} 5$ to 12 . The number of head shakes in calves treated with caustic paste appeared to increase at $12 \mathrm{~h}$, but it seems unlikely that this response would continue to be elevated in the hours that followed. A preliminary unpublished study by our research group followed pain responses for $24 \mathrm{~h}$ after caustic paste dehorning, and found no evidence of a sustained pain response in the period from 12 to $24 \mathrm{~h}$ following dehorning.

In the only other study comparing these 2 methods of dehorning, Morisse et al. (1995) examined behavioral and physiological responses of calves that were 1) dehorned using a hot iron with or without an anesthetic, and 2) dehorned using caustic paste with or without an anesthetic. As in the current study, these authors found no significant differences in behaviors such as head rubbing and head shaking between anesthetized and nonanesthetized calves dehorned with caustic paste. These results indicate that local anesthetic is not helping postoperative pain in the hours that follow dehorn- 
ing with caustic paste. Morisse et al. (1995) could not meaningfully compare responses between caustic paste and hot iron methods due to differences in calf age, although calves dehorned with caustic paste seemed to show less head rubbing and scratching than calves dehorned with a hot iron, a result that agrees with data from the current study.

In summary, caustic paste dehorning of calves sedated with xylazine results in a pain response, but local anesthesia with lidocaine provides no evidence of pain relief in the hours that follow application of the paste. The pain response in sedated calves dehorned with caustic paste is less than that following dehorning with a hot iron using both the sedative and local anesthetic. These results indicate that caustic paste dehorning with xylazine sedation might be a more humane, simpler, and less invasive procedure than hot-iron dehorning with sedation and local anesthesia.

\section{ACKNOWLEDGMENTS}

We thank the staff and students at the University of British Columbia's Animal Welfare Program and Dairy Education and Research Centre for their help throughout the study. This research was supported by the Natural Sciences and Engineering Research Council of Canada through the Industrial Research Chair in Animal Welfare, and by contributions from the Dairy Farmers of Canada, the BC Dairy Foundation, the BC Milk Producers, the BC SPCA, members of the BC Veterinary Medical Association and many other donors listed on our web site at www.agsci.ubc.ca/animalwelfare.

\section{REFERENCES}

Davies, J. W. L. 1982. Physiological Responses to Burning Injuries. Academic Press, London, UK.

de Jong, R. H. 1977. Local Anesthetics. 2nd ed. Charles C. Thomas Publ., Springfield, IL.

Faulkner, P. M., and D. M. Weary. 2000. Reducing pain after dehorning in dairy calves. J. Dairy Sci. 83:2037-2041.

Graf, B., and M. Senn. 1999. Behavioral and physiological responses of calves to dehorning by heat cauterization with or without local anaesthesia. Appl. Anim. Behav. Sci. 62:153-171.

Grøndahl-Nielsen, C., H. B. Simonsen, J. Damkjer Lund, and M. Hesselholt. 1999. Behavioral, endocrine and cardiac responses in young calves undergoing dehorning with or without the use of sedation and analgesia. Vet. J. 158:14-20.

Jasper, J., and D. M. Weary. 2002. Effects of ad libitum milk intake on dairy calves. J. Dairy Sci. 85:3054-3058.

Ley, S., A. Waterman, and A. Livingston. 1990. Variation in the analgesic effects of xylazine in different breeds of sheep. Vet. Rec. 126:508.

McMeekan, C. M., K. J. Stafford, D. J. Mellor, R. A. Bruce, R. N. Ward, and N. G. Gregory. 1998. Effects of regional analgesia and/or non-steroidal anti-inflammatory analgesics on the acute cortisol response to dehorning in calves. Res. Vet. Sci. 64:147-150.

Milligan, B. N., T. Duffield, and K. Lissemore. 2004. The utility of ketoprofen for alleviating pain following dehorning in young dairy calves. Can. Vet. J. 45:140-143.

Morisse, J. P., J. P. Cotte, and D. Huonnic. 1995. Effect of dehorning on behavior and plasma cortisol responses in young calves. Appl. Anim. Behav. Sci. 43:239-247.

Stafford, K. J., D. J. Mellor, S. E. Todd, R. N. Ward, and C. M. McMeekan. 2003. The effect of different combinations of lignocaine, ketoprofen, xylazine and tolazoline on the acute cortisol response to dehorning in calves. N.Z. Vet. J. 51:219-226.

Sylvester, S. P., D. J. Mellor, K. J. Stafford, R. A. Bruce, and R. N. Ward. 1998. Acute cortisol responses of calves to scoop dehorning using local anaesthesia and/or cautery of the wound. Aust. Vet. J. 76:118-122.

Veissier, I., J. Rushen, D. Colwell, and A. M. de Passillé. 2000. A laser-based method for measuring thermal nociception of cattle. Appl. Anim. Behav. Sci. 66:289-304.

Yano, K., Y. Hata, K. Matsuka, O. Ito, and H. Matsuda. 1993. Experimental study on alkaline skin injuries-periodic changes in subcutaneous tissue $\mathrm{pH}$ and the effects exerted by washing. Burns 19:320-323. 